\title{
Quality of life in ostomy patients: a qualitative study
}

\author{
This article was published in the following Dove Press journal: \\ Patient Preference and Adherence \\ 20 December 2010 \\ Number of times this article has been viewed
}

\section{Aazam Dabirian \\ Farideh Yaghmaei \\ Maryam Rassouli \\ Mansoureh Zagheri Tafreshi}

Nursing and Midwifery School, Shahid Beheshti University of Medical Sciences, Tehran, Iran
Correspondence: Aazam Dabirian Nursing and Midwifery School, Shahid Beheshti University of Medical Sciences, Vali Asr Street, Nyayesh Highway Cross, Tehran, Iran Tel +98 2I 88202519

$\mathrm{Fax}+982188202516$

Email aazamdabirian@yahoo.com
Purpose: Therapeutic procedures may not only treat disease but also affect patient quality of life. Therefore, quality of life should be measured in order to assess the impact of disease and therapeutic procedures. To identify clients' problems, it is necessary to assess several dimensions of quality of life, including physical, spiritual, economic, and social aspects. In this regard, we conducted a qualitative study to explore quality of life and its dimensions in ostomy patients referred to the Iranian Ostomy Association.

Methods: Fourteen patients were interviewed about their quality of life dimensions by purposeful sampling. Data were gathered by semistructured interviews and analyzed using the content analysis method.

Results: Nine main themes emerged using this approach, including physical problems related to colostomy, impact of colostomy on psychological functioning, social and family relationships, travel, nutrition, physical activity, and sexual function, as well as religious and economic issues.

Conclusion: The findings of the study identified a number of challenges in quality of life for patients with ostomy. The results can be used by health care providers to create a supportive environment that promotes better quality of life for their ostomy patients.

Keywords: ostomy, colostomy, qualitative study, quality of life

\section{Introduction}

Intestinal ostomy is a procedure that is implemented to treat several conditions, including acute diverticulitis, rectal cancer, trauma, or inflammatory bowel disease. This therapeutic approach can be temporary or permanent, and creates many challenges in terms of quality of life and functioning. In colostomy and ileostomy surgeries, normal bowel function is interrupted, and waste is passed through the abdominal wall through an opening called a stoma into an appliance that must be emptied periodically. Reasons for this surgery are varied, but the most common causes are colon cancer and inflammatory bowel disease. ${ }^{1,2}$

Although every effort is made to preserve intestinal and tissue integrity, a large number of patients undergo ostomy surgery each year. The purpose of ostomy is to treat and reduce patients' pain and discomfort, but in many cases ostomy leads to intensified distress and suffering for patients, and causes severe stress ${ }^{1}$ as a result of skin irritation $(76 \%)$, pouch leakage $(62 \%)$, offensive odor $(59 \%)$, reduction in pleasurable activities (54\%), and depression/anxiety (53\%). ${ }^{3}$ In such circumstances, it is worthwhile to assess quality of life in the evaluation of the outcomes of various therapeutic procedures along with their final impact on patients' lives. ${ }^{1}$ 
Making good decisions to control disease complications, treatment, and improving quality of life is a very important goal in treating and caring for patients with cancer. ${ }^{4}$ After surgery, many cancer patients with a stoma experience more stress and a variety of physical problems causing worry and shame. The stoma is usually red, swollen, and large immediately after surgery, which is unpleasant for the patient to look at for the first time. This emotional distress, along with physical problems and pain, isolation from others, and fear of death, will inevitably reduce quality of life further in ostomy patients. $^{5}$

In recent years, efforts to enhance quality of life in cancer patients as one of the important aims of treatment in oncology have encouraged health care providers to undertake more research to identify different dimensions of quality of life and effective ways to improve these. Nurses are important members of the health care team and have a significant role in caring for patients with cancer, in particular in identifying the needs of patients and their families, limiting complications of the disease, and improving quality of life $\mathrm{e}^{4}$ This study aimed to describe quality of life and its dimensions in patients with ostomy who were referred to the Iranian Ostomy Association in the Tehran province of Iran.

\section{Materials and methods}

Because qualitative enquiry depends on samples selected purposefully to investigate the phenomenon of interest, ${ }^{6}$ the 14 patients who volunteered to participate in this research were selected by purposeful sampling. Inclusion criteria included adequate physical and mental capability to participate, having had an ostomy in place for at least 6 months, freedom from other disease, and no history of ostomy in their family members that might influence the study results.

Following ethical approval, data were collected using semistructured audiotaped interviews. Each participant was informed of the purpose of the research and a consent form guaranteeing patient anonymity and confidentiality was signed. The subjects were able to withdraw from the study at any time. The time and place of the interview were arranged according to participants' preferences. Researchers attempted to arrange a calm and familiar environment in which the patients could be interviewed. Each interview lasted about 30-40 minutes. Data collection continued until saturation, ie, until the data emerging became repetitive and redundant. ${ }^{?}$

\section{Data analysis}

Because qualitative research can help to shape perceptions of a problem or situation, ${ }^{8}$ the content analysis method was chosen to capture the meaning of quality of life from the patient's perspective. Each interview was transcribed verbatim and then analyzed using the latent content analysis approach, whereby collection, coding, and analysis occur simultaneously. The information was coded and categorized in order to describe quality of life. Latent content analysis is the process of identifying, coding, and categorizing primary patterns in data obtained. Using this approach, the researcher seeks the meaning of specific points within the context of all the data, ${ }^{6}$ develops a categorization scheme, and then codes the data according to the categories. ${ }^{8}$ Therefore, in this study, the themes were categorized by identifying, exploring, and coding using the latent content analysis approach.

Strategies employed during the study to ensure accurate data collection and interpretation included:

- Selection of key informants, ie, patients living with ostomy who were willing to participate in the study voluntarily

- Reading of the transcripts by members of the team, followed by discussion and agreement on the themes identified until the point when saturation was reached

- Confirming the categories identified by the researchers by having two other experts separately coding segments of a sample of the transcripts as a peer check

- Return of the description of themes identified to the patient for validation (member check).

These strategies have been used previously for testing of credibility. ${ }^{9}$

\section{Findings}

The 14 participants in this study comprised six females and eight males, aged 14-57 years, with varying employment status, ie, employee, student, or self-employed. All participants, except for two, were married and had had a permanent colostomy due to cancer for 1-10 years. After analyzing the transcripts, nine main themes emerged.

\section{Physical problems}

Most participants complained of irritation and rash around the ostomy site, with sleep disturbance, bad breath, and gas emission in the presence of others. Moreover, they reported that they could not lift objects weighing more than $5 \mathrm{~kg}$. One of the participants said: "Can you imagine how a person who was always clean, with a fragrant body and having a healthy life style, has been changed to a person with bad body odor who cannot even tolerate himself!" It is noteworthy that most of the participants acknowledged the usefulness of ostomy education provided by the Iranian Ostomy Association but had not received any written information about it. 


\section{Psychological problems}

Patients in this study had some degree of cognitive and mental problems that they were concerned about. For example, one 47-year-old patient voiced concern about how his disease could affect his wife and children in the future. From the participants' perspective, an ongoing relationship with the Iranian Ostomy Association could address such concerns. Participants reported improved mood and ability to relax when they were able to have contact with fellow members of this association.

One of the participants stated: "I really owe the association and my friends who had experienced ostomy before me, because I didn't know anything about it and they did. They really helped me a lot".

\section{Social and family relationships}

Participants reported having encountered family problems for a few months after their colostomy, which gradually improved with time. One participant mentioned: "Our behavior influences our children's lives. If a man accepts his illness, his family will learn how to cope with it too. Then they will accept everything is okay".

On the other hand, some participants expressed a preference to avoid any family or school gatherings because of fear of offensive gas emission. One patient said: "Since experiencing this disease, I have not attended any family member's home for more than two years".

\section{Economic challenges}

Most patients reported that they had to change or leave their job after disease onset and their ostomy, and that this had affected their income. Moreover, disease-related costs, eg, buying bags and gloves, had caused further financial problems. One of the participants tried to describe this situation: "Imagine all of these people staying at home and being isolated from the community. I hope the Ostomy Association does something to overcome this problem. For example, $\mathrm{Mr}$... was a chief executive manager in his workplace, but after this disease, he lost his job and had to stay at home. Obviously, a healthy man with a top job is not the same as a sick man with bad body odor!"

Another participant mentioned a further economic problem caused by the disease: "Each bag costs 13,000-14,000 Rials, and we need at least one new bag daily, and if we don't watch our diet, we may need more than two bags per day. Most of us are just employees on a low salary, so how can we afford it?"

\section{Nutritional issues}

Most participants reported that although they did not receive any education about their diet and nutritional status, they considered it to be an important issue and were doing their best to control it. A 62-year-old woman said: "At first, I didn't know what I should eat. In the beginning, I had to change the bag 20 times every day! After a while, I gradually found that I could dry some plant buds and make a natural powder to eat, or mix it with milk or yoghurt. I found that I have to remove the skins of dates before eating them, to avoid obstruction".

\section{Physical activity}

Most participants reported limitation in physical activity after their ostomy. They stated that they have experienced a reduction in their usual activities and limitation in lifting heavy objects.

\section{Travel}

Although there is research reporting restrictions on traveling for ostomy patients as a quality of life issue, ${ }^{10,11}$ only one participant in our study mentioned traveling with a colostomy bag, commenting: "I traveled twice after having my colostomy for a long time, more than 20 hours. I know how to clean it before traveling and how to care for it during the trip".

\section{Religious considerations}

All of the participants in this study were Muslims, and most of them felt able to continue their religious rituals as usual. However, some considered that their religious rituals had been disrupted by colostomy. One of them said: "When I am going to pray in the Mosque, I feel I am not worthy enough to join the praying group, because I worry about my cleanliness for worship, prayer, and other religious tasks". However, none of the other participants reported any change in his/her belief in their God after colostomy.

\section{Sexual functioning}

In this study, married participants encountered some sexual problems, particularly early on in the course of their disease or after surgery, which resolved gradually with participation in discussion groups at the Iranian Ostomy Association. One participant stated: "After surgery I was worried about my relationship with my husband. I felt ashamed at first, but after communication with other women with similar conditions in the association and participating in counseling sessions with my spouse, my worry was decreased". 


\section{Discussion}

The literature shows that ostomy patients experience many challenges in relation to their quality of life. ${ }^{1,3,5,12-14}$ The findings of our study similarly highlighted a range of quality of life problems and challenges. Colostomy is a surgical procedure intended to decrease gastrointestinal symptoms and prevent disease progression, but the inevitable changes in physical appearance led to disordered bodily function and disruption of a number of aspects of the patients' private lives. ${ }^{1,15}$

In the present study, the impact of ostomy on patient quality of life was explored across many dimensions. The physical problems related to ostomy, including irritated peristomal skin, odor, and noise from the appliance mentioned by participants, have been reported by other investigators. ${ }^{3,15,16}$ Also, the emotional and mental concerns described by patients in this study have been reported by Adel Mehraban et al. ${ }^{5}$ Mitchell et al further showed that leakage, odor, and noise from the appliance were the primary sources of embarrassment identified by patients. ${ }^{15}$

The findings of our study are also consistent with those of other researchers who have shown that economic problems can affect quality of life for ostomy patients. Coons et al have demonstrated that the cost of colostomy is an important quality of life consideration. ${ }^{14}$ Nichols and Riemer have further referred to loss of employment as one of the consequences of a stoma. ${ }^{17}$

Ostomy surgery and its associated problems may affect the patients' relationship with their intimate partners. ${ }^{17}$ According to Brown and Randle, patients with stomas tend to worry about sexual issues, ${ }^{18}$ and our findings did highlight sexual problems among participants, especially in the early period after surgery and stoma formation, leading to further impairment of quality of life..$^{10,12,13,18}$ In a study by Symms et al, it was shown that almost half of patients who were sexually active before ostomy surgery became inactive after the procedure. ${ }^{13}$ Therefore, referral for counseling and evaluation of sexual health may be appropriate.

Many problems reported by the participants in our study were related to the early period after surgery and colostomy. It should be noted that at the time of data gathering for this research, most of the participants had already gradually adapted to and coped with their ostomy-related problems, so specific care and consideration of these issues should be implemented as soon as possible after surgery. ${ }^{1,19,20}$ Passage of time is the most important factor in adapting successfully to life with an ostomy. Many of the problems, such as changes in body appearance, anxiety about fecal leakage from the ostomy bag, offensive odor, bowel noise, and loss of libido, have been found to decrease over time. ${ }^{19}$

Health care providers should make every attempt to improve quality of life in their ostomy patients, and nurses in particular should be aware that their knowledge and skills can help to enhance quality of life before and after ostomy surgery. ${ }^{21}$

Body image can be defined as the perception of physical appearance and function that forms gradually following birth, which can be impaired easily, in particular in people with diseases treated by ostomy. ${ }^{18}$ Therefore, it is important to help these patients to adapt successfully to a new phase in their lives by providing appropriate pre- and postoperative education. Pittman et al found that many factors, including age, income, employment, preoperative care (stoma site marking and education), and time since surgery, were related to severity of ostomy complications. ${ }^{22}$ If patients receive appropriate care, they can cope with ostomy and regain their independence over a period of 2-3 weeks or less. They should receive continuing consultation and support to identify and address their emotional and psychological needs. Because the degree of problems experienced by ostomy patients largely relates to their experience and skill in self-care, patients have the best chance of returning to their usual lives if they receive continuing education during the transition from hospital to their homes. Nurses have an important role to play in ongoing training and guidance. . $^{3,21,22}$

Another important finding in this study relates to religious issues. Although most participants stated that they did not have a major problem with this dimension, it is still very important for nurses to pay attention to spiritual dimensions and the religious rituals of their clients. As with many religions, it is important in Islam to be clean and free of any fecal material, especially when praying, so nurses need to optimize patient hygiene as far as possible.

Although using a qualitative approach leads to better understanding and insight into coping and acceptance of life with ostomy from the patient's perspective, ${ }^{1}$ the findings of this study cannot necessarily be extrapolated to wider populations with the same degree of certainty as may be the case with quantitative analyses. This is because the findings of qualitative research cannot be tested for statistical significance. ${ }^{7-9}$ Another limitation of our research is the selection of participants from the Iranian Ostomy Association, who had already participated in a number of counseling sessions and group discussions to cope with life after ostomy.

However, our findings may still be useful for health care providers when creating a supportive environment to improve 
quality of life in ostomy patients. Using interviews and openended questions provides an opportunity for participants to express their concerns about quality of life issues. We could not show any relationship or correlation between demographic characteristics and quality of life in this research due to the qualitative approach used.

\section{Acknowledgments}

The authors are grateful to all the participants in this study. This project was approved and funded by the research committee of the Shahid Beheshti Medical Sciences University, Tehran, Iran. We are also grateful for the collaboration and support of the Iranian Ostomy Association during this research.

\section{Disclosure}

The authors report no conflicts of interest in this work.

\section{References}

1. Krouse RS, Grant M, Rawl SM, et al. Coping and acceptance: The greatest challenge for veterans with intestinal stomas. J Psychosom Res. 2009;66:227-232.

2. Smith DM, Loewenstein G, Rozin P, Sherriff RL, Ubel PA. Sensitivity to disgust, stigma, and adjustment to life with a colostomy. J Res Pers. 2007;41:787-803.

3. Richbourg L, Thorpe JM, Rapp CG. Difficulties experienced by the ostomate after hospital discharge. J Wound Ostomy Continence Nurs. 2007;34:70-79.

4. Aghabarari M, Ahmadi F, Mohammadi E, Hajizadeh E, Farahani A. Physical, spiritual, psychological and social dimensions of quality of life in breast cancer women receiving chemotherapy. Nurs Res. 2006;3:55-65.

5. Adel Mehraban M, Ashoori E, Moladoost A, Aghayi S. Psychological experiences of patients with surgical stoma (colostomy): A phenomenological study. Res Behav Sci. 2008;2:119-127.

6. Mayan MJ. An Introduction to Qualitative Methods: A Training Module for Students and Professionals. Alberta, Canada: International Institute for Qualitative Methodology; 2001.
7. Streubert HJ, Carpenter DR. Qualitative Research in Nursing. 3rd ed. Philadelphia, PA: Lippincott Co; 2003.

8. Polit DF, Beck CT. Essentials of Nursing Research: Method, Appraisal, and Utilization. 6th ed. Philadelphia, PA: Lippincott Williams \& Wilkins Co; 2005.

9. Gerrish K, Lacey A. The Research Process in Nursing. 5th ed. Oxford: Blackwell Publishing; 2006.

10. Krouse R, Grant M, Ferrell B. Quality of life outcomes in 599 cancer and non-cancer patients with colostomies. J Surg Res. 2007;138:79-87.

11. Shultz JM. Preparing the patient for colostomy care: A lesson well learned. Ostomy Wound Manage. 2002;48:22-25.

12. Sprangers MAG, Taal BG, Aaronson NK, Velde A. Quality of life in colorectal cancer, stoma vs nonstoma patients. Dis Colon Rectum. 1995;38:361-369.

13. Symms MR, Rawl SM, Grant M, et al. Sexual health and quality of life among male veterans with intestinal ostomies. Clin Nurse Spec. 2008;22:30-40.

14. Coons SJ, Chongpison Y, Wendel CS, Grant M, Krouse RS. Overall quality of life and difficulty paying for ostomy supplies in the VA Ostomy Health-Related Quality of Life Study: An exploratory analysis. Med Care. 2007;45:891-895.

15. Mitchell KA, Rawl SM, Schmidt CM, et al. Demographic, clinical, and quality of life variables related to embarrassment in veterans living with an intestinal stoma. $J$ Wound Ostomy Continence Nurs. 2007;34:524-532.

16. Lynch BM, Hawkes AL, Steginga SK, Leggett B, Aitken JF. Stoma surgery for colorectal cancer: A population-based study of patient concerns. J Wound Ostomy Continence Nurs. 2008;35:424-428.

17. Nichols T, Riemer M. The impact of stabilizing forces on postsurgical recovery in ostomy patients. $J$ Wound Ostomy Continence Nurs. 2008;35:316-320.

18. Brown H, Randle J. Living with a stoma: A review of the literature. J Clin Nurs. 2005;14:74-81.

19. Ohman U. Prognosis in patients with obstructive colorectal carcinoma Am J Surg. 1982;143:742-747.

20. Hocevar B, Gray M. Intestinal diversion (colostomy or ileostomy) in patients with severe bowel dysfunction following spinal cord injury. J Wound Ostomy Continence Nurs. 2008;35:159-166.

21. Black PK. Psychological, sexual, and cultural issues for patients with the stoma. Br J Nurs. 2004;13:692-695.

22. Pittman J, Rawl SM, Schmidt CM, et al. Demographic and clinical factors related to ostomy complications and quality of life in veterans with ostomy. J Wound Ostomy Continence Nurs. 2008;35:493-503.
Patient Preference and Adherence

\section{Publish your work in this journal}

Patient Preference and Adherence is an international, peer-reviewed, open access journal focusing on the growing importance of patient preference and adherence throughout the therapeutic continuum. Patient satisfaction, acceptability, quality of life, compliance, persistence and their role in developing new therapeutic modalities and compounds to

\section{Dovepress}

optimize clinical outcomes for existing disease states are major areas of interest. This journal has been accepted for indexing on PubMed Central. The manuscript management system is completely online and includes a very quick and fair peer-review system. Visit http://www.dovepress.com/ testimonials.php to read real quotes from published authors. 